\title{
PROFESSOR C. J. HAMSON
}

THE Editorial Committee record with great regret the death on 14 November 1987 of Professor C. J. Hamson, Emeritus Professor of Comparative Law, who was Editor of the Journal from 1955 to 1973 and its Treasurer from 1953 to 1973.

A brief biographical note was published in [1974] C.L.J. 1, together with extracts from the address which Professor Hamson gave at the dinner held by the Law Faculty in his honour on his retirement in October 1973. 